\title{
Detecting nests of lapwing birds with the aid of a small unmanned aerial vehicle with thermal camera
}

\author{
Martin Israel $^{1}$, Aline Reinhard ${ }^{2}$
}

\begin{abstract}
Due to increasingly dense agricultural land use, many ground breeding birds are threatened with extinction or near threatened. We present a new method, to detect lapwing and other ground breeding bird nests. A small UAV with a thermal camera is suitable to detect a lapwing nest from a flight altitude of $40 \mathrm{~m}$. With the aid of a special thermal camera image preprocessing algorithm the contrast could be enhanced by 10 to $50 \%$ which improves the detectability of nests. We successfully demonstrated, that we detected $93 \%$ of the known nests. This paper describes and analyzes the necessary conditions for optimal lapwing nest detection with a UAV borne thermal camera.
\end{abstract}

\section{INTRODUCTION}

Lapwing (Vanellus vanellus) is a migratory bird, originally breeding in meadows, pastures, moist meadows, ponds and moors. Due to the increasingly dense cultivation lapwings tend to breed more and more often in harvested agricultural fields [24]. Without special conservation measures, most of the early eggs fall victim to the agricultural soil processing in the cultivated land [15].

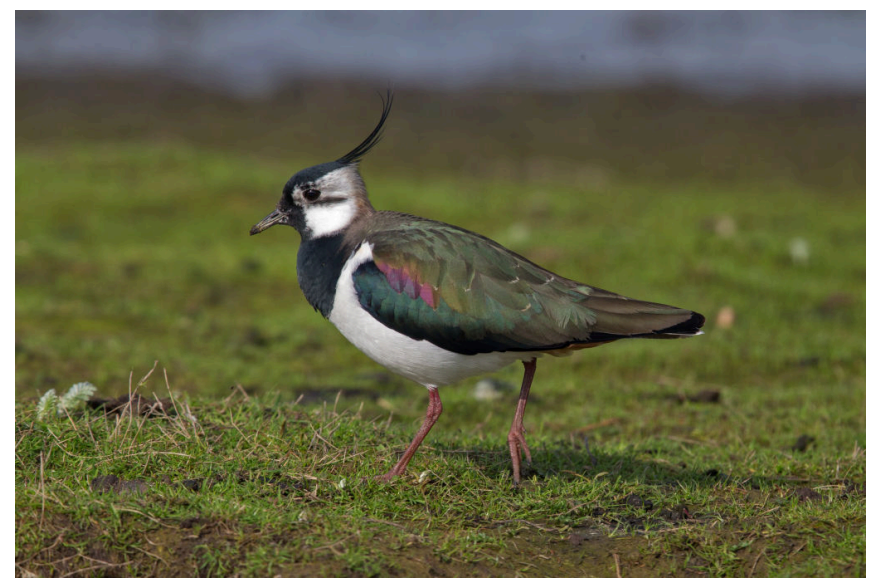

Fig. 1. Northern Lapwing, Image by A.Trepte, www.photo-natur.de

As many other ground breeding birds the lapwing is listed in the IUCN Red List of Threatened Species. Since 2015 it is classified as near threatened.

The nesting site is chosen such that the lapwing, when it sits on the nest during breeding season, has a wide view of the surrounding area in order to escape early when predators approach. The eggs and the nests are well camouflaged in order not to be easily found by predators [22] (see figs. 2).

\footnotetext{
${ }^{1}$ Remote Sensing Technology Institute, German Aerospace Center, 82234 Oberpfaffenhofen, Germany martin.israeledlr. de

2 NABU-Naturschutzstation Münsterland, 48165 Münster, Germany a.reinhardenabu-station.de
}
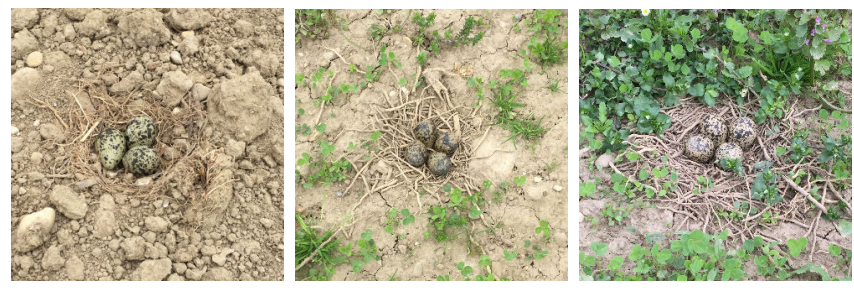

Fig. 2. Three of the four lapwing nests, we found during the flight Wsb5.

Finding the nests and then marking them, so that the farmer omits this spot while plowing, can lead to a population increase. Then islands remain like in fig. 3. It was shown,

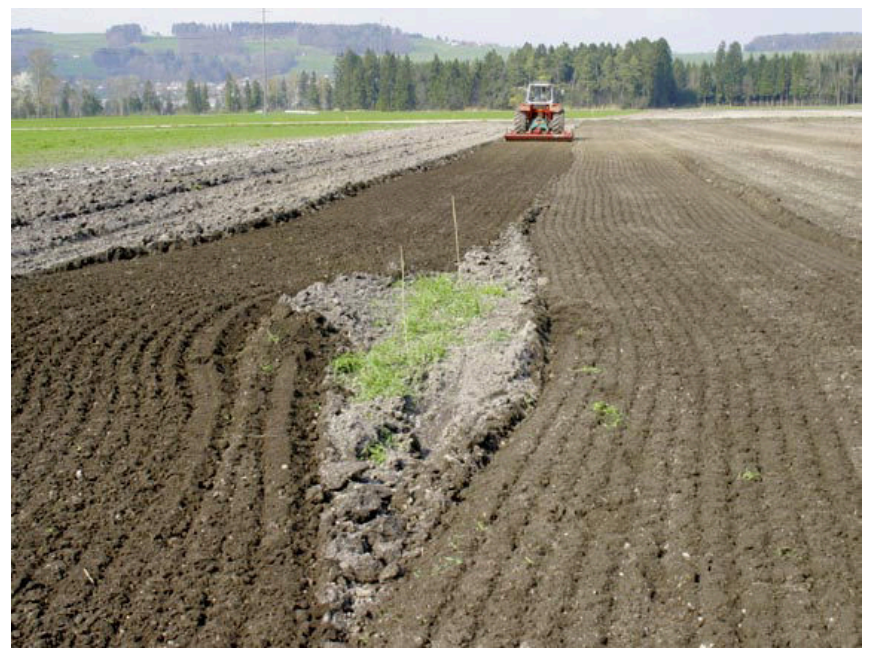

Fig. 3. To save the lapwing nest, the farmer avoided the nest site by leaving a small patch uncovered by the machines. Image by L. Schifferli [21].

that this activity alone is often not sufficient to reach the minimum necessary 0.8 chicks per breeding couple for preserving the lapwing species [16]. Around two third of the destroyed nests are due to predators. Schifferli [20] has shown that fencing the nest with an electric fence leads to a successful increase of the population.

\section{A. THE CLASSIC APPROACH}

The classic method to find lapwing nests is illustrated in fig. 4. With a spotting scope or binoculars out of the car, parked at the border of the field, you can observe the lapwing sitting on the clutch. Some binoculars are equipped with a laser distance sensor. On approach the bird flies away. Therefore you can steer for a tree or something else in bearing direction directly behind the bird and keep an eye 


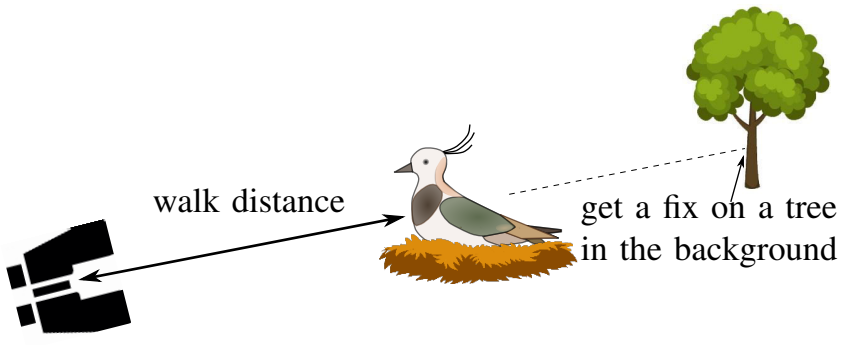

Fig. 4. The classic method to find a breeding nest.

on it while approaching. The lapwing usually flies away at an approaching distance of 50 to $100 \mathrm{~m}$. The correct approaching distance can be verified by targeting the car.

There is just few documentation about the technique to detect ground breeding bird nests [17, 27]. In contrast to most ground breeding raptors [6] it is mostly easy to detect the breeding lapwing bird from far away. But it is time consuming to locate the nest at close range. The method with a drone and a thermal camera, which is presented here, could help to find the nests faster. Some nests are nearly impossible to find with the classic approach due to occlusion by hilly landscape or vegetation.

\section{B. USING A UAV}

Several wildlife scientists nowadays recognize the potential of airborne cameras as an alternative to classical observation with binoculars: "Unmanned aircraft systems (UAS) are remote-controlled devices capable of collecting information from difficult-to-access places while minimizing disturbance." [19]. It can be a good alternative to observe wild animals from a tree [3]. Airborne thermal imaging for wildlife observation is also becoming increasingly popular: "Thermal imaging cameras are widely used to observe and detect wild animals and their habitats, and to estimate their population size. Temperature distributions do not have to be measured accurately, and animals appear as warm spots against a dark, cool background in the thermogram, which is sufficient to confirm their presence. The fact that such observations can be performed remotely creates a wealth of new opportunities for wildlife researchers" [5]. Havens and Sharp recognized already in 1998 that using a thermal camera instead of a visual camera for detecting wildlife animals leads to more accurate detection [7].

A suitable UAV size for lapwing clutch detection is a miniature or small UAV (SUAV, $<25 \mathrm{~kg}$ ) or Micro Aerial Vehicle (MAV). The flightpath should be automated, to not oversee a nest. Especially at such homogeneous scenes like agricultural fields it is very difficult to keep the track while manually flying.

The automated flight with rotorcraft UAVs can be divided into two different modes. The waypoint and the timelapse mode. In the waypoint mode the UAV approaches waypoint by waypoint. At each waypoint one or more images are captured. The waypoints are arranged so that the captured images overlap to a certain extent. In timelapse mode the camera is timely triggered e.g. every second. Alternatively a video could be captured during overflight. The waypoint mode has the advantage that the acquired data is more precise and exact. The disadvantage is the lower area coverage per time.

Besides the flight there are two further tasks for detecting lapwing nests: detecting the eggs on the image and locating the eggs on the agricultural field which requires georeferenced data. The focus of this paper is on the visual image detection task and the justification of the flight parameters.

\section{MATERIALS \& METHODS}

The overwhelming majority of lapwing clutches has four eggs. The size of an egg is $47 \times 33 \mathrm{~mm}$ on average [22]. With an idealized circular nest with $9 \mathrm{~cm}$ diameter and square shaped camera pixels the maximum ground sampling distance (GSD) $d_{\mathrm{GSD}}$ is at $3.18 \mathrm{~cm}$. In this case there is a situation where four complete pixel receive only radiation from the nest (fig. 5 left). Slightly shifting the camera might lead to a worst case scenario, where only one pixel completely receives only radiation from the nest (fig. 5 right). The maximum GSD

$$
d_{\mathrm{GSD}}=\frac{r_{\text {nest }}}{\sqrt{2}}
$$
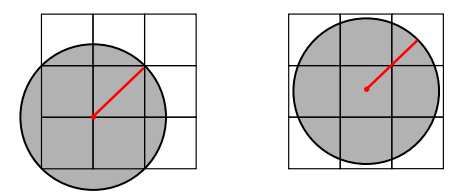

Fig. 5. The gray circle represents an idealized clutch with radius $r_{\text {nest }}$ (marked red). The checker pattern represents the pixels. Here, the maximum possible GSD is shown to have at least one pixel that collects radiation only from the nest.

With the aid of the GSD, the focal length $c_{\mathrm{k}}$ and the size $s$ of a detector element the maximum flight altitude $h_{\mathrm{f}}$ can be calculated by

$$
h_{\mathrm{f}}=\frac{d_{\mathrm{GSD}} \cdot c_{\mathrm{k}}}{s} .
$$

With our thermal camera, that has a focal length $c_{\mathrm{k}}$ of $19 \mathrm{~mm}$ and a pixel pitch $s$ of $17 \mu \mathrm{m}$ the maximum flight altitude allowing to correctly measure the real temperature of a lapwing nest is $35.5 \mathrm{~m}$.

We use a small rotorcraft UAV, which we also use for the detection of roe deer fawns during the meadow mowing season $[8,26]$. The UAV is a Falcon 8 from Ascending Technologies (now a part of Intel). The payload consists of a Tau 640 thermal infrared (IR) camera with $19 \mathrm{~mm}$ optics from FLIR and a camera in the visible (VIS) spectral range. Here we use the GoPro 3 Black Plus Edition with custom narrow field of view optics (Sunix DSL936). Fig. 6 shows the system. The image raw data of the thermal camera and some georeferencing data from the UAV are recorded on a SD-Card by a special data logger (called FlirSD) from Ascending Technologies. Beside the data recorder on board, the UAS can send the live video of the cameras via 
an analogue video transmitter to the ground station. FLIR Cameras manufactured before 2013 have a fixed 5\% so called tail rejection for the analogue video out interface. The 5\% hottest pixels of the image are jointly set to the maximum pixel value. This makes it nearly impossible to detect lapwing nests. The higher quality raw images on the SD-Card are much better suited for the detection of lapwing nests. Nevertheless, the live stream helps for the pilots guidance during manual flights. With $5800 \mathrm{mAh} \mathrm{LiPo}$ batteries the UAV can fly 12 minutes. We use the timelapse mode strategy to achieve maximum coverage area per time.

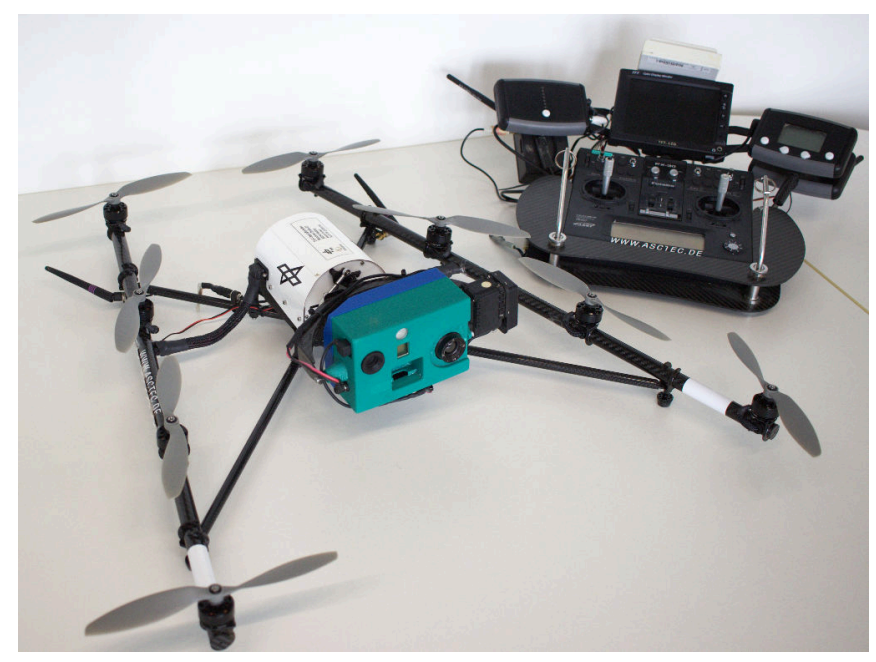

Fig. 6. Falcon 8 from Ascending Technologies. Inside the green payload box there is an IR and a VIS camera.

During the work on finding roe deer fawns with our UAS we have developed a strategy that we also use to find lapwing nests. Figure 7 shows the workflow in a diagram. The first

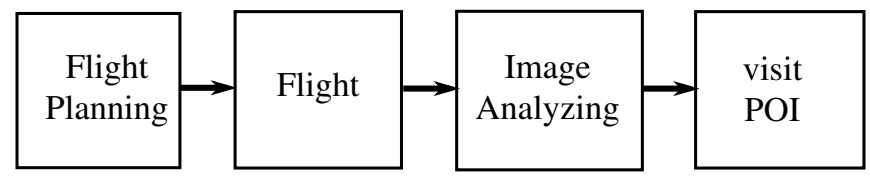

Fig. 7. Current workflow to detect and mark lapwing nests.

step is the software based flight planning. The area of interest is marked by a polygon on a map. Our flight planning software [12] calculates a suitable flight path. After that, the UAV starts flying. During overflight with constant velocity the cameras acquire images every second and save them on SD-Cards together with the GPS position, camera orientation, time and some other UAV Sensor Data. The gimbal controls the orientation of the cameras. For this application they are downward oriented. The system flies automatically from waypoint to waypoint until the whole area is covered. The pilot only needs to interfere in emergency cases. After the flight the image analyzing step follows. For that, the SD-Card with the raw data is read out. With the position and pose information at the time of image acquisition and the elevation model of the scene, detected Points of Interest
(POI) can be georeferenced. The GPS positions of these POIs are then transmitted to a hand-held GPS device. In the last step a person walks with the aid of the GPS device to each of the POIs and marks the lapwing nests with two bars like in fig. 3 in case of a true positive classification. The farmer now knows where the nests are and leaves these patches untreated. In [9] different search strategies are compared with the focus on practical use and high area efficiency. Although the strategy in fig. 7 is sequential, in case of roe deer fawn detection it results in a more reliable detection and a higher area output compared to a parallel approach with live monitoring and marking during the flight. For lapwing nest detection we have no such comparison, but we assume equivalent results.

To not get blurred images, its important that the UAV flies not too fast. Depending on the flight altitude $h_{\mathrm{f}}$, the maximum flight velocity is

$$
v\left(h_{\mathrm{f}}\right)=\frac{h_{\mathrm{f}} \cdot p \cdot s}{t_{\mathrm{i}} \cdot c_{\mathrm{k}}},
$$

with the camera integration time $t_{\mathrm{i}}$, the focal length $c_{\mathrm{k}}$ and the size $s$ of a detector element of the focal plane array (FPA). At this speed the motion blur is in the range of $p$ pixels.

There are two types of thermal cameras: cooled photon detector and uncooled microbolometer cameras. For the limited payload weight of small UAVs and especially of MAVs, uncooled microbolometer cameras are currently the only reasonable. The FPAs of microbolometer cameras nowadays are mostly one of the two material types: Vanadium Oxid (VOx) or amorphous Silicon ( $\alpha$-Si) [18]. They have different characteristics. Especially the integration time $t_{\mathrm{i}}$ is distinct. Fig. 8 shows the flight velocity $v$ as a function of flight altitude $h_{\mathrm{f}}$ where the images have a one pixel motion blur when the camera is looking downward. Typical integration times are: $t_{\mathrm{i}}(\mathrm{VOx})=15 \mathrm{~ms}, t_{\mathrm{i}}(\alpha-\mathrm{Si})=7 \mathrm{~ms}$.

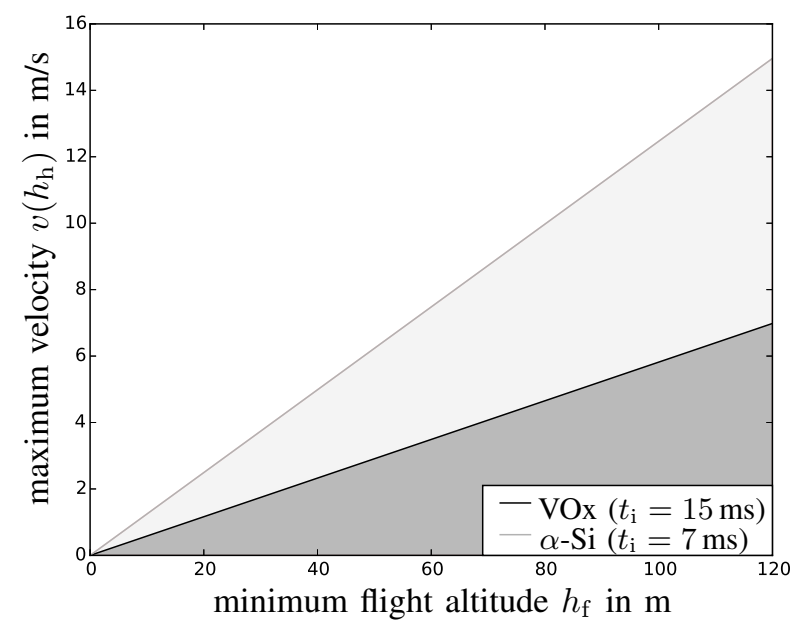

Fig. 8. Integration time limited horizontal flight velocity for the used Tau 640 camera with Vanadium Oxid (VOx) FPA. If only the FPA is exchanged with an amorphous silicon $(\alpha-\mathrm{Si})$ FPA the UAV could fly with more than the double speed.

The temperature measured with uncooled microbolometer 
cameras can differ from contact thermometers. Reasons for that are for example wrong adjustment of the emission level, mixing pixels, motion blur or influences of the optics like wrong focus. Our camera is calibrated, but due to the fact that it is an unstabilized imager camera the measured absolute radiation temperature has a variability of about 2-3 Kelvin. The biggest influence in practical use cases with rotor UAV overflights might be motion blur and mixing pixels.

The measuring principle for microbolometers is the heating of a very small temperature-dependent resistor, which requires a certain fixed integration time $t_{\mathrm{i}}$ due to its thermal mass. If motion blur happens, measuring a small warm object surrounded by cold background will underestimate the target temperature. Beside the warm object the microbolometer is irradiated by the cold surrounding during the fixed integration time.

Uncooled microbolometer cameras have another particularity: Changing the camera housing temperature has a five times higher influence on the measured temperature as a temperature change in the scene [1]. Therefore one can often see a vignetting like effect on microbolometer captured images especially in temperature changing environment or during the camera warm up phase. To improve the detectability of small hotspots like lapwing nests on thermal images, we apply the Microbolometer Optimization (MbOpt) algorithm (see fig. 9) to the images before they are visually analyzed [10].

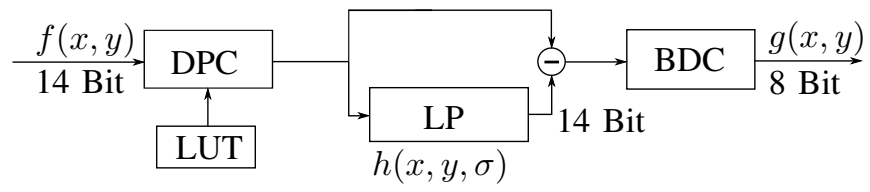

Fig. 9. Block diagram of the MbOpt algorithm for image preprocessing.

The first step is a Dead Pixel Correction (DPC) based on a Look Up Table (LUT) with known dead pixels. The second step is a Low Pass Filter with a kernel size $\sigma$ of $147 \times 147$ pixel applied on the 14 Bit raw image. The last step is a Bit Depth Compression (BDC) to convert the 14 Bit to the visualizable 8 Bits per channel of a computer monitor.

\section{RESULTS}

At six different days in three different areas we performed 17 flights and detected 15 nests. Table I shows some relevant information on the campaigns. The first nine flights (Mns1Mns9) were accomplished on 17. and 18. of April 2015 around Münster in Germany, where the Nabu Naturschutzstation Münsterland (a non-governmental nature conservation organization) takes care of the lapwing population. Hausen (Hsn1 and Hsn2) was the second area, $40 \mathrm{~km}$ west of Munich. Two flights took place at the very cloudy 2nd May of 2015. The third area was near Wasserburg (Wsb1-Wsb6). Flights were realized during the breeding seasons 2015 and 2016 in cooperation with the lower nature conservation authority of Rosenheim.

Table I shows the flight name, date and local time of the UAV landing for each flight. Moreover it shows the number of nests found, the weather, the cloud coverage in $x / 8$ and the surface air temperature at the time of the flight.

The flights were performed at different altitudes between 30 and 80 meters. The captured images had an overlap of 30 percent across track. Along track, the overlap varied from at least $30 \%$ to a maximum of $95 \%$.

\begin{tabular}{|c|c|c|c|c|}
\hline Flight & Date, Time & Nests & Weather & Temp \\
\hline Mns1 & 2015-04-17 18:51 & 1 & sun/cld 2/8 & $14^{\circ} \mathrm{C}$ \\
\hline Mns2 & 2015-04-17 19:24 & 1 & sunset $2 / 8$ & $13^{\circ} \mathrm{C}$ \\
\hline Mns3 & 2015-04-17 20:13 & $1^{*}$ & sun down & $12{ }^{\circ} \mathrm{C}$ \\
\hline Mns4 & 2015-04-18 15:45 & 3 & sun/cld 2/8 & $15^{\circ} \mathrm{C}$ \\
\hline Mns5 & 2015-04-18 16:20 & $3 *$ & sunny $2 / 8$ & $16^{\circ} \mathrm{C}$ \\
\hline Mns6 & 2015-04-18 17:29 & 0 & sunny $1 / 8$ & $15^{\circ} \mathrm{C}$ \\
\hline Mns7 & 2015-04-18 17:55 & 0 & sunny $1 / 8$ & $15^{\circ} \mathrm{C}$ \\
\hline Mns8 & 2015-04-18 19:22 & 0 & sunny $0 / 8$ & $15^{\circ} \mathrm{C}$ \\
\hline Mns9 & 2015-04-18 19:29 & 2 & sunset $0 / 8$ & $16^{\circ} \mathrm{C}$ \\
\hline Hsn1 & $2015-05-02 \quad 16: 25$ & 2 & covered $8 / 8$ & $13^{\circ} \mathrm{C}$ \\
\hline Hsn2 & $2015-05-02 \quad 16: 34$ & 0 & covered $8 / 8$ & $13^{\circ} \mathrm{C}$ \\
\hline Wsb1 & 2015-05-05 10:26 & 1 & cloudy $1 / 8$ & $24^{\circ} \mathrm{C}$ \\
\hline Wsb2 & 2015-05-05 11:25 & 1 & sunny $1 / 8$ & $27^{\circ} \mathrm{C}$ \\
\hline Wsb3 & 2016-04-11 11:29 & 0 & sunny $1 / 8$ & $11^{\circ} \mathrm{C}$ \\
\hline Wsb4 & 2016-04-11 11:57 & 0 & sunny $1 / 8$ & $12{ }^{\circ} \mathrm{C}$ \\
\hline Wsb5 & 2016-05-10 11:02 & 4 & cloudy $4 / 8$ & $20^{\circ} \mathrm{C}$ \\
\hline Wsb6 & 2016-05-10 12:29 & 0 & cloudy $4 / 8$ & $20^{\circ} \mathrm{C}$ \\
\hline
\end{tabular}

THE 17 EXECUTED FLIGHTS WITH THE AMOUNT OF DETECTED NESTS, THE UAVS LANDING TIMES AND SOME ENVIRONMENT DATA.

Fig. 10 shows the two flights Mns8 (green) and Mns9 (blue). The green and blue dots indicate the position of

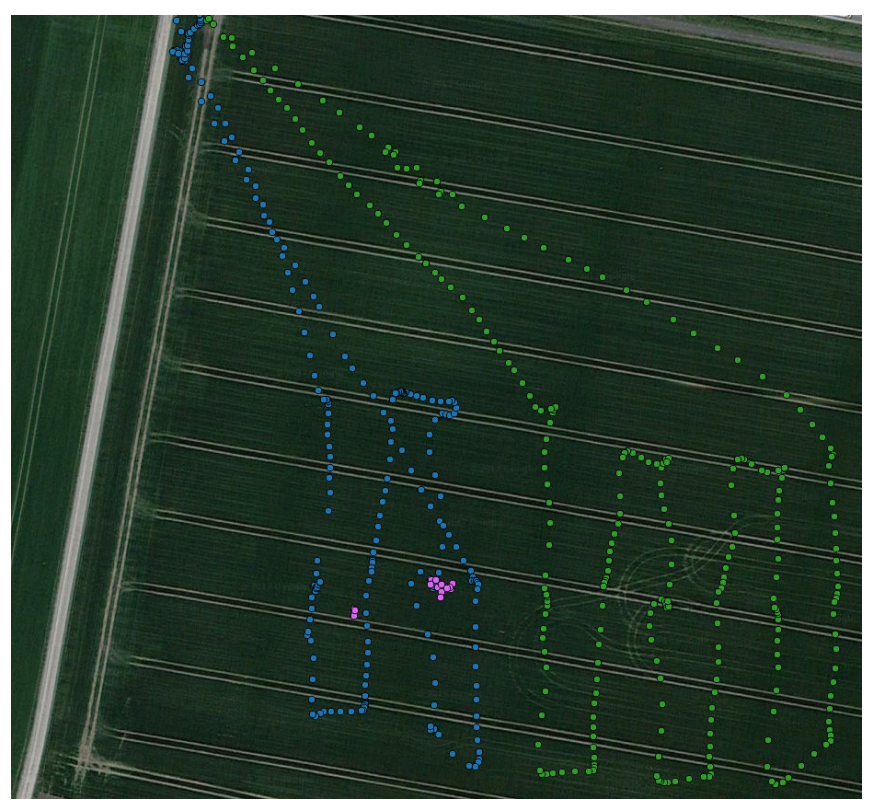

Fig. 10. The flightpath of two flights above a field, where two lapwing nests (pink points) were found. Background Satellite Image is from Google Maps / Digital Globe 2017.

a captured image. The pink spots mark the reprojected positions (out of the images) of the two lapwing nests

* The same nests as found during the flight above. 
8 and 9. Due to missing ground control points and less matching tiepoint features in the thermal images, indirect georeferencing using bundle adjustment, as usually practiced in aerial photogrammetry $[13,25]$, can not be used to calculate the position of the nests. For this reason, direct georeferencing from [9] was used. Above all, the inaccurate position measurement on the dynamic UAV, but also the absence of reference points, causes an uncertainty of up to $5 \mathrm{~m}$ at $40 \mathrm{~m}$ flight altitude [9].

The first thing we wanted to find out is if we can find lapwing nests at all. For this purpose, we have selected areas on which breeding nests have already been marked and omitted while plowing (see fig. 3). These omitted spots appear even on thermal images as conspicuous islands.

It turned out that one could actually discover the lapwing nests from $30 \mathrm{~m}$ flight altitude. As suspected, the lapwing flew away as the UAV approached. The warm eggs could be detected and at the first nest we measured a difference of about $10 \mathrm{~K}$ between the radiation temperature of the eggs and their surrounding environment. At an altitude of $30 \mathrm{~m}$ with our thermal camera with an FOV of about $30^{\circ}$, the nest was mapped to about $4 \times 4$ pixels.

After it was clear that the eggs are detectable with the thermal camera at $30 \mathrm{~m}$, we tried to fly above the field Mns2 where we suspected also lapwing nests. This field was not yet plowed and therefore represented a more realistic situation. Fig. 11 shows that the nest was very easy to detect in the thermal image. The field had a measured radiation temperature between 6.2 and $13.9^{\circ} \mathrm{C}$ in the fig. 11. The nest had a radiation temperature of $27.9^{\circ} \mathrm{C}$.

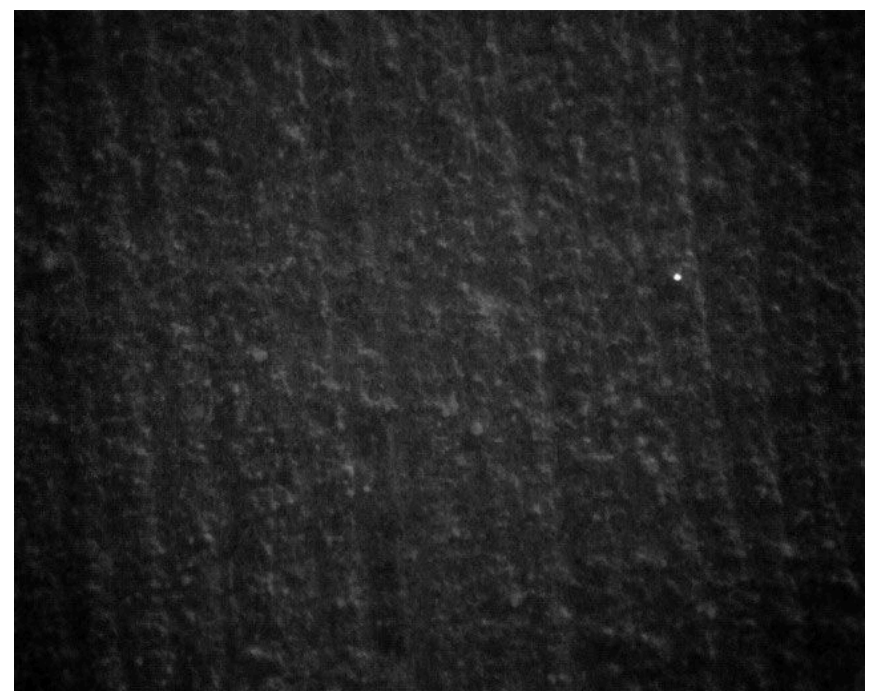

Fig. 11. Thermal image, captured during flight Mns2 at an altitude of $30 \mathrm{~m}$. The lapwing nest is easily detectable.

Fig. 12 shows the same nest from approx. $2 \mathrm{~m}$ distance. Although we knew that a nest must lie within a radius of $5 \mathrm{~m}$, we found it difficult to find it immediately. It was very well camouflaged.

Table II shows the most important flight path information. The first three flights were performed at an altitude of $30 \mathrm{~m}$.

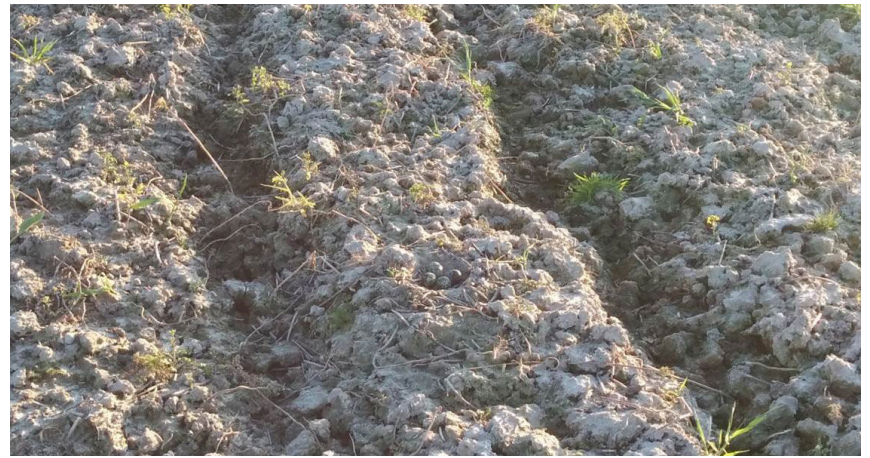

Fig. 12. The Nest from Mns2 ans Mns3. Hard to detect even if you are just $2 \mathrm{~m}$ away.

The UAV stopped at waypoints each 40 to $60 \mathrm{~m}$ to rectify the flight path. The maximum flight speed was at $5.5 \mathrm{~m} / \mathrm{s}$, but due to the many stops the average speed is at $2.1 \mathrm{~m} / \mathrm{s}$.

\begin{tabular}{llrlll}
\hline Flight & Area & Duration & Area/min & Speed & Altitude \\
\hline Mns1 & 3.5 ha & $10: 04$ & $0.35 \mathrm{ha} / \mathrm{min}$ & $2.1 \mathrm{~m} / \mathrm{s}$ & $30 \mathrm{~m}$ \\
Mns2 & $2.1 \mathrm{ha}$ & $10: 19$ & $0.20 \mathrm{ha} / \mathrm{min}$ & $1.0 \mathrm{~m} / \mathrm{s}$ & $30 \mathrm{~m}$ \\
Mns3 & $2.3 \mathrm{ha}$ & $7: 59$ & $0.28 \mathrm{ha} / \mathrm{min}$ & $2.3 \mathrm{~m} / \mathrm{s}$ & $30 \mathrm{~m}$ \\
Mns4 & $7.9 \mathrm{ha}$ & $7: 17$ & $1.08 \mathrm{ha} / \mathrm{min}$ & $2.1 \mathrm{~m} / \mathrm{s}$ & $80 \mathrm{~m}$ \\
Mns5 & $6.7 \mathrm{ha}$ & $9: 18$ & $0.72 \mathrm{ha} / \mathrm{min}$ & $2.2 \mathrm{~m} / \mathrm{s}$ & $60,40 \mathrm{~m}$ \\
Mns6 & $1.6 \mathrm{ha}$ & $6: 29$ & $0.25 \mathrm{ha} / \mathrm{min}$ & $1.7 \mathrm{~m} / \mathrm{s}$ & $40 \mathrm{~m}$ \\
Mns7 & $1.6 \mathrm{ha}$ & $4: 42$ & $0.34 \mathrm{ha} / \mathrm{min}$ & $2.1 \mathrm{~m} / \mathrm{s}$ & $40 \mathrm{~m}$ \\
Mns8 & $4.6 \mathrm{ha}$ & $4: 15$ & $1.08 \mathrm{ha} / \mathrm{min}$ & $2.4 \mathrm{~m} / \mathrm{s}$ & $40 \mathrm{~m}$ \\
Mns9 & $2.3 \mathrm{ha}$ & $4: 16$ & $0.54 \mathrm{ha} / \mathrm{min}$ & $2.4 \mathrm{~m} / \mathrm{s}$ & $40 \mathrm{~m}$ \\
Hsn1 & $4.9 \mathrm{ha}$ & $8: 03$ & $0.61 \mathrm{ha} / \mathrm{min}$ & $2.1 \mathrm{~m} / \mathrm{s}$ & $40 \mathrm{~m}$ \\
Hsn2 & $4.6 \mathrm{ha}$ & $6: 44$ & $0.68 \mathrm{ha} / \mathrm{min}$ & $2.5 \mathrm{~m} / \mathrm{s}$ & $40 \mathrm{~m}$ \\
Wsb1 & $1.6 \mathrm{ha}$ & $3: 54$ & $0.41 \mathrm{ha} / \mathrm{min}$ & $0.6 \mathrm{~m} / \mathrm{s}$ & $40,20 \mathrm{~m}$ \\
Wsb2 & $0.7 \mathrm{ha}$ & $4: 44$ & $0.15 \mathrm{ha} / \mathrm{min}$ & $1.6 \mathrm{~m} / \mathrm{s}$ & $20-70 \mathrm{~m}$ \\
Wsb3 & $6.6 \mathrm{ha}$ & $6: 24$ & $1.03 \mathrm{ha} / \mathrm{min}$ & $2.7 \mathrm{~m} / \mathrm{s}$ & $40 \mathrm{~m}$ \\
Wsb4 & $4.6 \mathrm{ha}$ & $7: 06$ & $0.65 \mathrm{ha} / \mathrm{min}$ & $2.8 \mathrm{~m} / \mathrm{s}$ & $40 \mathrm{~m}$ \\
Wsb5 & $6.3 \mathrm{ha}$ & $6: 39$ & $0.95 \mathrm{ha} / \mathrm{min}$ & $3.4 \mathrm{~m} / \mathrm{s}$ & $40 \mathrm{~m}$ \\
Wsb6 & $4.5 \mathrm{ha}$ & $5: 30$ & $0.81 \mathrm{ha} / \mathrm{min}$ & $2.5 \mathrm{~m} / \mathrm{s}$ & $40 \mathrm{~m}$ \\
\hline
\end{tabular}

FLIGHT PATH INFORMATION FOR EACH FLIGHT.

The flight Mns4 was at an altitude of $80 \mathrm{~m}$. We wanted to test if the eggs are still visible at this altitude. With a high flight altitude one gets a broad coverage per image. Therefore the area at this single high altitude flight is the maximum of all flights. Mns5 was a flight at $60 \mathrm{~m}$. Most of the other flights have been performed at $40 \mathrm{~m}$. This altitude seemed to be a good trade off between area performance and high nest detectability. From Mns8 on we increased the distance between the waypoints along track, to get a more continuous flight speed and a higher area performance. On the very warm days of Wsb1 and Wsb2 we tested again different flight altitudes. At these two flights the area/min values are not meaningful due to longer hovering above the nest at different altitudes.

In fig. 13 the maximum temperatures $T_{\text {nest }}$ of all nests found are displayed in red. In green, average temperatures $T_{\text {sur }}$ of a 2 to 4 pixel ring around the respective nest is displayed. The difference $\Delta T=T_{\text {nest }}-T_{\text {sur }}$ between the two graphs is also shown in blue in the diagram. The horizontal 
axis labeling of the diagram includes the Nest Id and the Flight Id.

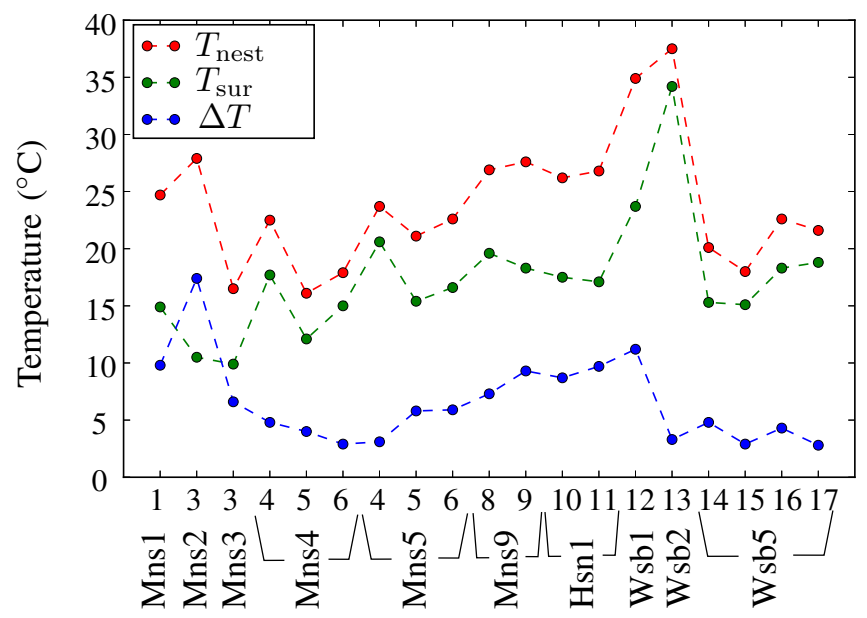

Lapwing Nests by Id and Flight

Fig. 13. Maximum temperatures of all nests found are shown in red. Their direct surrounding temperature are drawn in green and the difference between both graphs is drawn in blue.

The nests 3, 4, 5, 6 and 7 were each flown over twice. The nest 7 could not be discovered on the thermal images, although parallel to the flight the lapwing was observed with binoculars as it sits on the nest. The nest 2 was also not discovered, but here is not clear: 1. whether it was in range of the UAV overflights and 2. whether the eggs were still in the clutch.

The table III shows the temperature values of the images that displays a nest with maximum contrast. For fig. 13 these values are used, too. The column Dif is a subjective

\begin{tabular}{llllllll}
\hline Id & Flight & $T_{\text {nest }}{ }^{\dagger}$ & $\Delta T^{\dagger}$ & Dif & $T_{\max }{ }^{\dagger}$ & $T_{\min }^{\dagger}$ & $\sum I_{\text {nest }}$ \\
\hline 1 & Mns1 & 24.7 & 9.8 & 2 & 21.4 & 9.2 & 5 \\
2 & Mns1 & & & 4 & & & 0 \\
3 & Mns2 & 27.9 & 17.4 & 1 & 13.9 & 6.2 & 5 \\
3 & Mns3 & 16.5 & 6.6 & 1 & 12.3 & 4.2 & 50 \\
4 & Mns4 & 22.5 & 4.8 & 3 & 26.5 & 11.0 & 5 \\
5 & Mns4 & 19.7 & 4.0 & 4 & 23.9 & 7.5 & 8 \\
6 & Mns4 & 20.5 & 2.9 & 4 & 24.2 & 10.6 & 23 \\
4 & Mns5 & 23.7 & 3.1 & 3 & 30.8 & 13.5 & 11 \\
5 & Mns5 & 21.1 & 5.8 & 3 & 28.8 & 5.8 & 10 \\
6 & Mns5 & 23.1 & 5.9 & 3 & 26.8 & 10.7 & 14 \\
7 & Mns6 & & & 4 & & & 0 \\
8 & Mns9 & 26.9 & 7.3 & 2 & 24.8 & 11.4 & 15 \\
9 & Mns9 & 27.6 & 9.3 & 2 & 22.1 & 11.6 & 4 \\
10 & Hsn1 & 26.2 & 8.7 & 1 & 20.3 & 13.1 & 6 \\
11 & Hsn1 & 26.8 & 9.7 & 1 & 20.6 & 13.9 & 3 \\
12 & Wsb1 & 34.9 & 11.2 & 2 & 29.3 & 16.1 & 25 \\
13 & Wsb2 & 37.5 & 3.3 & 2 & 35.7 & 28.6 & 26 \\
14 & Wsb5 & 20.1 & 4.8 & 2 & 19.3 & 9.8 & 5 \\
15 & Wsb5 & 18.0 & 2.9 & 3 & 19.2 & 10.0 & 3 \\
16 & Wsb5 & 22.6 & 4.3 & 2 & 20.3 & 15.0 & 2 \\
17 & Wsb5 & 21.6 & 2.8 & 2 & 20.3 & 15.0 & 3 \\
\hline
\end{tabular}

TABLE III

TEMPERATURE VALUES OF THE IMAGES THAT SHOW A NEST WITH MAXIMUM CONTRAST. assessment of the difficulty of detection the nest on the images. Here 1 means very simple, 2 is medium, 3 is hard and 4 is not found. In addition, the minimum temperature for each image, on which the maximum nest temperature $T_{\text {nest }}$ was measured, is listed. For $T_{\max }$ the lapwing nests have been cut out of the images, to determine the maximum temperature of the field background. The column $\sum I_{\text {nest }}$ shows the number of images on which the respective nest was found due to image overlap or explicit hovering above the nest.

At the flight Mns2 for example, 5 images were recorded on which the nest can be seen. For the nest, maximum temperatures of 21.4 to $27.9^{\circ} \mathrm{C}$ were measured. Due to mixing pixels and motion blur, the best suited image for Mns2 is therefore the one with $27.9^{\circ} \mathrm{C}$.

In order to not oversee a nest, no automatic detection algorithm as in [2, 11] or [23, 4] was used. Instead, the images were visually evaluated. For improving the detectability during visual evaluation the MbOpt algorithm was applied. It leads to a contrast enhancement of 10 to $50 \%$ depending on the extent of thermal drift of the camera housing. The assessment of the detection difficulty was made with the images that were preprocessed with the MbOpt algorithm. Fig. 14 shows an image with and without the MbOpbt algorithm applied.
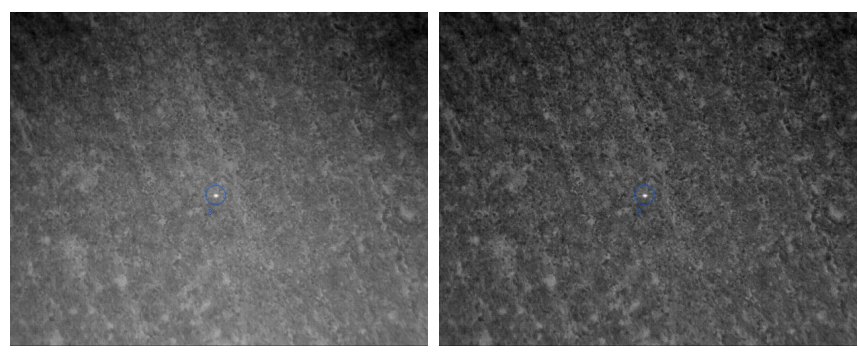

Fig. 14. The Nest 3 during the Flight Mns3 without (left) and with applying the MbOpt algorithm (right). The contrast improvement on this image is $25 \%$.

In addition to the thermal images, VIS images were also recorded every second on the flights in Münster. Fig. 15 shows the VIS image that was captured at the same time as fig. 11. The nest location is indicated by a red circle.

\section{DISCUSSION}

Lapwing nests can be easily detected with a thermal camera at low irradiance conditions, e.g. when the sky is overcast or after sunset. It is quite different with the color images of the GoPro camera. Finding a lapwing nest on them is as difficult as finding a needle in the haystack (see fig. 15).

The lapwing nest temperature $T_{\text {nest }}$ is clearly above the maximum temperature $T_{\max }$ of the remaining scene. This is shown in fig. 11. In this simplest case, the difference temperature $T_{\text {nest }}-T_{\max }$ was $14 \mathrm{~K}$. However, the difference temperature $\Delta T$ between nest and immediate surroundings

${ }^{\dagger}$ All Temperatures are given in ${ }^{\circ} \mathrm{C}$. 


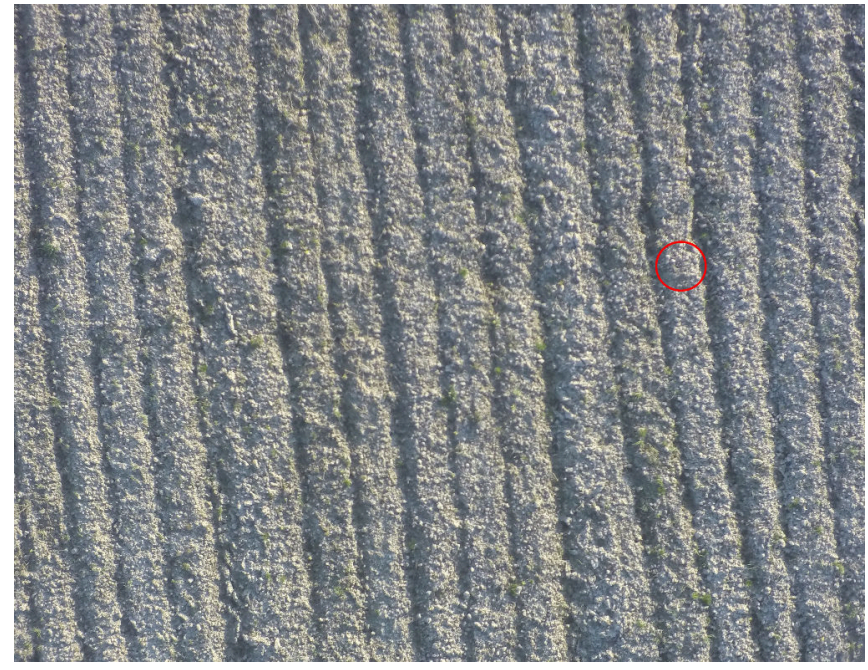

Fig. 15. VIS image, captured during flight Mns2 at an altitude of $30 \mathrm{~m}$. The red circle marks the position of the lapwing nest.

is more reliable than $T_{\text {nest }}-T_{\max }$. Even in this simple case, $\Delta T$ is $3.4 \mathrm{~K}$ greater than $T_{\text {nest }}-T_{\max }$.

If you compare the $\Delta T$ column with the Dif column in table III, it is noticeable that in the easy-to-detect lapwing nests $\Delta T \geq 6.6 \mathrm{~K}$. According to the experiments, it looks as if one can detect a lapwing nest well at a difference temperature of $\Delta T>6 \mathrm{~K}$. This also seems to be the case with difficult air temperature and weather conditions.

\section{A. Standard Deviation Temperature $\bar{\sigma}$}

However, the difference temperature alone is not sufficient to distinguish all easily detectable nests from the difficultly detectable nests. The nest 17 from the flight Wsb5 has, for example, a difference temperature $\Delta T_{17}=2.9 \mathrm{~K}$ in relation to its environment. The detection difficulty was rated as 2 (medium). At nest 5 from flight Mns $5 \Delta T_{5}=5.8 \mathrm{~K}$ is twice the size of $\Delta T_{17}$. However, the detection difficulty was rated as 3 (difficult). Fig. 16 shows this image. With the diagram in fig. 17 you can explain why it is so difficult. It shows the averaged standard deviation

$$
\bar{\sigma}(f)=\frac{1}{n_{f}} \sum_{i=1}^{n_{f}} \sigma_{f, i},
$$

with $n_{f}$ as the amount of images showing only agricultural fields without lapwing nests and the standard deviation $\sigma_{f, i}$ of the pixel values of the image with the number $i$ during the flight with the id $f$.

On fields with very uniform temperature warm spots are much easier to detect than on fields with large temperature differences. Therefore $\bar{\sigma}$ is a good measure for the a priori estimation of the detectability of lapwing nests.

It seems that detection is difficult from $\bar{\sigma}=1.2 \mathrm{~K}$ on. At all nests that were found to be hard to detect, $\bar{\sigma}>1.2 \mathrm{~K}$. However, with 17 flights the sample size is too low for a robust statistical statement.

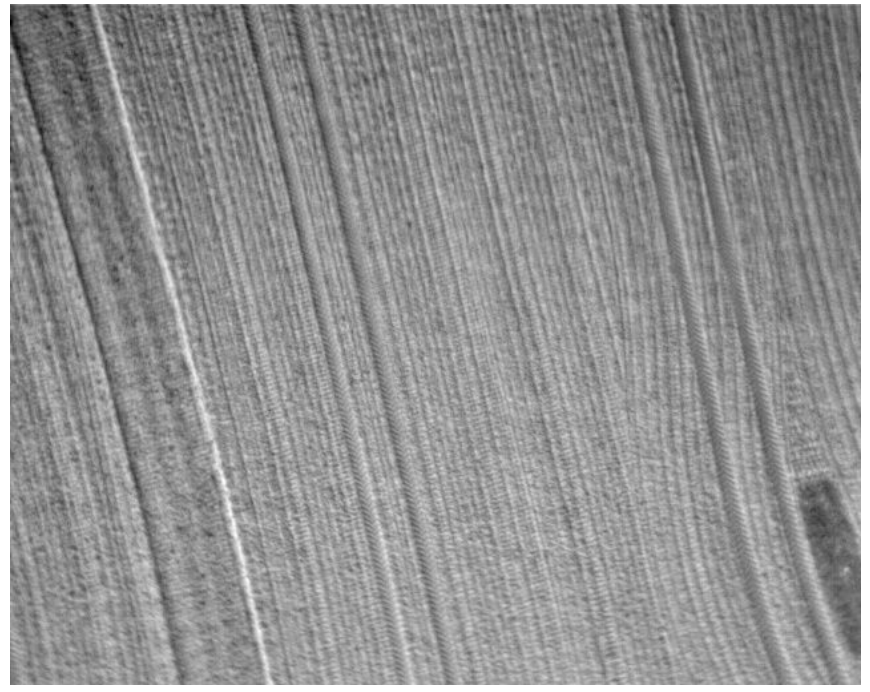

Fig. 16. Not so easy to detect Nest 5. Although there is left an island while plowing.

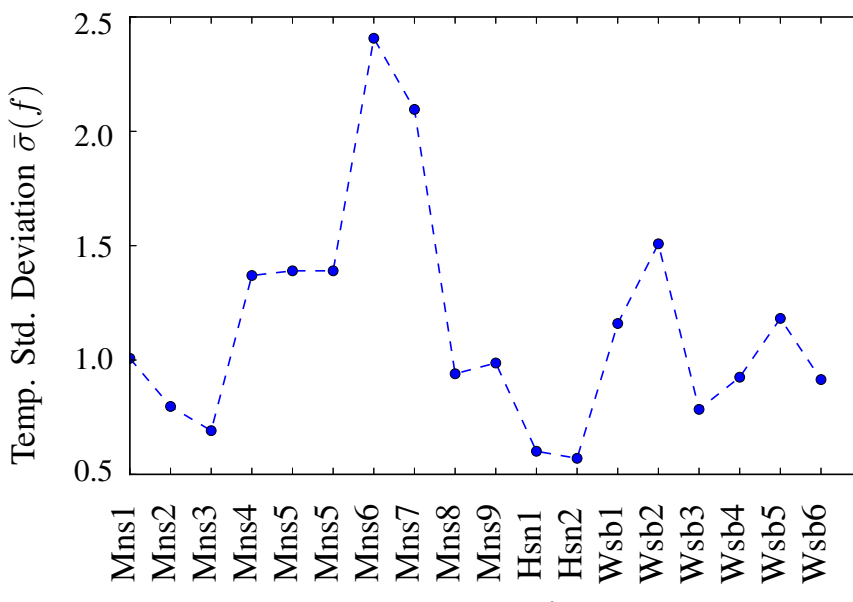

Flights $f$

Fig. 17. Average standard deviation of the radiation temperature of the agricultural fields for the 17 flights.

The irradiance of the sun contributes to a high standard deviation of the temperatures in homogeneous fields. At flights after sunset or when the sky is completely covered (like Mns3, Hsn1 or Hsn2) the fields have a more uniform temperature than on sunny days. $\bar{\sigma}$ is less than $0.7 \mathrm{~K}$ for these flights. For flights at sunshine, $\bar{\sigma}>1 \mathrm{~K}$. This shows, the detectability of the nests depends on the irradiance.

\section{B. Flight Altitude and Velocity}

In addition to the irradiance, the flight altitude and speed also play an important role in the detection. With the assumption that a nest is circular with $r_{\text {nest }}=4.5 \mathrm{~cm}$ and has a constant temperature everywhere, equation 1 and 2 lead to a result of $35.5 \mathrm{~m}$ as the maximum altitude for our camera. If you fly higher, the risk of misrepresenting the measured values because of mixing pixels increases. Nest 4 at flight Mns4 shows that a nest can be detected even under moderate conditions at $80 \mathrm{~m}$ altitude. 
For the detectability, the influence of the flight speed is not as problematic as it seems. With equation 3 one can calculate the size $p$ of motion blur (in pixels). But the nests are often recognizable even in very blurry images. This may be because the output voltage $u(t)$ of a detector element is not linearly dependent on the integration time $t$, but as follows:

$$
u(t)=U_{\max }\left(1-e^{-\frac{t}{\tau}}\right)
$$

All flights were performed with a maximum flight speed of approx. $5.5 \mathrm{~m} / \mathrm{s}$. Since the UAV stops at each waypoint, the average speed is usually between 2 and $3 \mathrm{~m} / \mathrm{s}$ (see table II). Most flights were at an altitude of $40 \mathrm{~m}$. Since the camera has a FPA based on VOx, approximately $50 \%$ of the images are out of focus (see equ. 3 and fig. 8). But due to the generous overlap there is at least one sharp picture of each nest. For accurate georeferencing, however, a constant-velocity flight would be much better. The largest georeferencing error was measured during acceleration and deceleration of the UAV.

Flying higher and faster leads to a larger area coverage per time. Especially if a field is very large more than one flight is necessary to cover the entire area. This can have fatal consequences for the brood of the birds (see section IV-C). Therefore, efforts should be made to achieve the highest possible area coverage per time.

\section{Biological Aspects}

At nest 3, which has been flown over twice at $30 \mathrm{~m}$, one can see the cooling of the eggs in fig. 13. In between both flight the bird was sitting on the nest. But since the sun has gone down already, the eggs cooled down strongly. It is possible that the eggs of this nest have fallen below the critical physiological zero temperature at about $25^{\circ} \mathrm{C}$ [14]. If the temperature is below this, no chick can hatch from the eggs. Therefore, in addition to the detection reliability and the area coverage performance, the optimization must also ensure that the eggs do not cool too much. The next day the bird was no longer sitting on the nest.

The nests 4, 5 and 6 were first flown over at $80 \mathrm{~m}$, and shortly thereafter at $60 \mathrm{~m}$. The bird on Nest 5 stayed on the nest during the flights. Only when the UAV reached the nest at an altitude of 40 meters, the bird flew away. If you compare nest 5 with nest 4 at flight Mns4 in fig. 13, you can see that the feathers of the outgrown bird emits significantly less radiation than the eggs of nest 4 . Nest 6 could not be observed with binoculars in flight Mns4 and Mns5, so it is not quite clear whether the eggs or the brooding bird is visible on the images. At the other 14 observed nests, the breeding pairs left their area during the UAV flights mostly without or with few mobbing calls. They observed the further course of the disturbance from the distance. Lapwing birds are often mobbing and scaring away flying enemies such as birds of prey or crows. Such an enemy behavior could not be observed against the UAV. After landing it, the birds returned to their breeding grounds within a few minutes. The UAV does not seem particularly dangerous to the birds.

\section{Chicks and Other Species}

At the two flights Hsn1 and Hsn2, besides the nests it seems that also 8 lapwing chicks could be discovered. At an altitude of $40 \mathrm{~m}$, a chick is represented on only one to four pixels in the image. But they are clearly visible as small hotspots with an average difference temperature $\Delta T=3.6 \mathrm{~K}$ to the surrounding. They were just detected on the images and no evaluation was performed. But due to the large amount of lapwings in this area, the date and the amount of hotspots it is plausible that this are the lapwing chicks of two nests. For other ground breeding species this method could also be applied. Especially for detecting marsh and montagu's harrier (Circus aeruginosus and Circus pygargus) nests a UAV born thermal camera was used already.

\section{CONCLUSION}

We could demonstrate that it's possible to detecting lapwing nests with the aid of a UAV based thermal camera. It seems that even smaller bird nests could be detected with this method.

The optimal environment condition for detecting lapwing nests is a warm day with completely overcast sky. On warm days the eggs cool down slower. Then a longer disturbance does not harm the breeding success. An overcast sky improves the detectability on the thermal images. A flight altitude of $40 \mathrm{~m}$ is well-suited to incite the breeding lapwing to fly away. With a $19 \mathrm{~mm}$ thermal optics and a $17 \mu \mathrm{m}$ FPA the GSD is at $3.6 \mathrm{~cm}$ at this altitude and large enough to reliably detect the nests under nearly all conditions. A constant flight velocity that leads to a motion blur of 1 to 2 pixels is a good trade off between area coverage performance and detectability. For our thermal camera with VOx FPA this is approx. $3 \mathrm{~m} / \mathrm{s}$ at $40 \mathrm{~m}$ flight altitude. With the aid of the MbOpt algorithm the contrast of the images can be enhanced significantly. This leads to a better visual detectability of the lapwing nests.

\section{ACKNOWLEDGMENT}

Thanks to Margit Böhm from the lower nature conservation authority Rosenheim for the possibility to test the UAVbased system at the lapwing nests near Wasserburg. Thanks to Peter Haschberger for reviewing this paper.

\section{REFERENCES}

[1] Helmut Budzier and Gerlach Gerald. Thermische Infrarotsensoren. WILEY-VCH Verlag $\mathrm{GmbH} \& \mathrm{Co}$. KGaA, Weinheim, 2010, p. 309. ISBN: 978-3-52740960-0.

[2] Daniele Cerra, Martin Israel, and Mihai Datcu. "Parameter-free clustering: Application to fawns detection". In: Geoscience and Remote Sensing Symposium, 2009 IEEE International, IGARSS 2009. Vol. 3. IEEE. 2009, pp. 467-469.

[3] Dominique Chabot and David M Bird. "Evaluation of an off-the-shelf unmanned aircraft system for surveying flocks of geese". In: Waterbirds 35.1 (2012), pp. $170-174$. 
[4] Peter Christiansen et al. "Automated detection and recognition of wildlife using thermal cameras". In: Sensors 14.8 (2014), pp. 13778-13793.

[5] Justyna Cilulko et al. "Infrared thermal imaging in studies of wild animals". In: European Journal of Wildlife Research 59.1 (2013), pp. 17-23.

[6] Mark R Fuller and James A Mosher. Raptor survey techniques. US Fish and Wildlife Service, 1987.

[7] Kirk J Havens and Edward J Sharp. "Using thermal imagery in the aerial survey of animals". In: Wildlife Society Bulletin (1998), pp. 17-23.

[8] Martin Israel. "A UAV-based roe deer fawn detection system". In: International Archives of Photogrammetry and Remote Sensing 38 (2011), pp. 1-5.

[9] Martin Israel. "Entwicklung eines UAV-basierten Systems zur Rehkitzsuche und Methoden zur Detektion und Georeferenzierung von Rehkitzen in Thermalbildern: Der Fliegende Wildretter". PhD thesis. Universität Osnabrück, 2015.

[10] Martin Israel. "UAV-gestützte Detektion von Kiebitznestern in Agrarflächen”. In: Computer-Bildanalyse in der Landwirtschaft (2017).

[11] Martin Israel and Stephan Evers. "Mustererkennung zur Detektion von Rehkitzen in Thermalbildern". In: Bornimer Agrartechnische Berichte (2011), pp. 1-6.

[12] Martin Israel, Manuel Mende, and Stefan Keim. "UAVRC, a generic MAV flight assistance software". In: International Archives of the Photogrammetry, Remote Sensing and Spatial Information Sciences XL1/W4 (2015), pp. 287-291.

[13] K Kraus. Photogrammetrie. De-Gruyter-Lehrbuch Bd. 1. Bod Third Party Titles, 2004. ISBN: 9783110177084.

[14] Terje Lislevand. "Male incubation in Northern Lapwings: effects on egg temperature and potential benefits to females". In: Ornis Fennica 78 (2001), pp. 2329.

[15] W Müller et al. "Wirkung von Massnahmen für den Kiebitz Vanellus vanellus in der Schweiz und Empfehlungen für die Artenförderung". In: Der Ornithologische Beobachter 106.3 (2009), pp. 327-350.

[16] WJ Peach, PS Thompson, and JC Coulson. "Annual and long-term variation in the survival rates of British lapwings Vanellus vanellus". In: Journal of Animal Ecology (1994), pp. 60-70.

[17] PF Donald RD Gregory DW Gibbons. Bird census and survey techniques in Bird ecology and conservation: a handbook of techniques. Oxford University Press, 2004.

[18] A Rogalski. "Recent progress in infrared detector technologies". In: Infrared Physics \& Technology 54.3 (2011), pp. 136-154.

[19] FRANCESC SARDÀ-PALOMERA et al. "Fine-scale bird monitoring from light unmanned aircraft systems". In: Ibis 154.1 (2012), pp. 177-183.

[20] Luc Schifferli, Reto Spaar, and Andreia Koller. "Fence and plough for Lapwings: Nest protection to improve nest and chick survival in Swiss farmland". In: $O s$ nabrücker Nat. wiss. Mitt 32 (2006), pp. 123-129.

[21] Luc Schifferli et al. "Massnahmen zur Förderung des Kiebitzes Vanellus vanellus im Wauwilermoos (Kanton Luzern): Schutz der Nester vor Landwirtschaft und Prädation”. In: Ornithol. Beob 106 (2009), pp. 311326.

[22] Michael Shrubb. The lapwing. Bloomsbury Publishing, 2010.

[23] Kim Arild Steen et al. "Automatic detection of animals in mowing operations using thermal cameras". In: Sensors 12.6 (2012), pp. 7587-7597.

[24] Stefan R Sudmann et al. "Entwicklung der Kiebitzbestände Vanellus vanellus in Nordrhein-Westfalen von 1850 bis 2014”. In: Charadrius 50 (2014), pp. 2331.

[25] Bill Triggs and PF McLauchlan. "Bundle adjustment - a modern synthesis". In: Vision algorithms: theory and practice 34099 (2000), pp. 1-71.

[26] Tilman Wimmer et al. "Rehkitzrettung mit dem Fliegenden Wildretter: Erfahrungen der ersten Feldeinsätze". In: 19. Workshop ComputerBildanalyse in der Landwirtschaft 2. Workshop Unbemannte autonom fliegende Systeme (UAS) in der Landwirtschaft. 81. 2013, pp. 85-95.

[27] Maiken Winter et al. "Guidelines for finding nests of passerine birds in tallgrass prairie". In: USGS Northern Prairie Wildlife Research Center (2003), p. 160. 